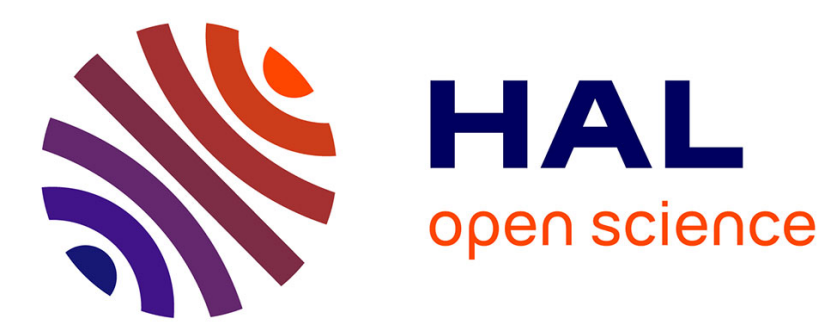

\title{
PDAs and Handhelds: ICT at your side and not in your face
}

\author{
Jocelyn Wishart, Andy Ramsden, Angela Mcfarlane
}

\section{To cite this version:}

Jocelyn Wishart, Andy Ramsden, Angela Mcfarlane. PDAs and Handhelds: ICT at your side and not in your face. Technology, Pedagogy and Education, 2007, 16(1), pp.95-110. hal-00190014

\section{HAL Id: hal-00190014 https://telearn.archives-ouvertes.fr/hal-00190014}

Submitted on 23 Nov 2007

HAL is a multi-disciplinary open access archive for the deposit and dissemination of scientific research documents, whether they are published or not. The documents may come from teaching and research institutions in France or abroad, or from public or private research centers.
L'archive ouverte pluridisciplinaire $\mathbf{H A L}$, est destinée au dépôt et à la diffusion de documents scientifiques de niveau recherche, publiés ou non, émanant des établissements d'enseignement et de recherche français ou étrangers, des laboratoires publics ou privés. 


\section{PDAs and Handhelds: ICT at your side and not in your face}

Jocelyn Wishart $^{1}$, Andy Ramsden ${ }^{2}$ and Angela McFarlane ${ }^{1}$

${ }^{1}$ Graduate School of Education, University of Bristol.

${ }^{2}$ Learning Technology Support Service, Institute of Learning and Research Technology, University of Bristol

Address: Dr J.M. Wishart, University of Bristol, 35 Berkeley Square, Bristol, UK. BS8 1JA Tel: 01179287055 Fax: 01179287110

Email: j.m.wishart@bris.ac.uk 


\title{
PDAs and Handhelds: ICT at your side and not in your face
}

Keywords: Handheld Computers, Teacher Training, Innovation, Mobile Learning

\begin{abstract}
Personal Digital Assistants (PDAs) or handheld computers have been shown to support teachers in the management of course information, pupil assessment information, knowledge acquisition, task organisation and communication (Becta, 2003). The latest PDAs now come with internal cameras and mobile phones allowing the user to communicate via voice and text as well as accessing the internet. This paper stems from a trial at the Graduate School of Education in the University of Bristol supported by the Training and Development Agency for Schools (TDA) and set up to evaluate the potential of such devices to support initial teacher training (ITT) students in science.
\end{abstract}

Fourteen students were given PDAs selected to represent the range of then currently available PDAs with mobile phone connectivity in the UK. As a result the following areas were identified by ITT students as definitely being of support during their course; the calendar or diary scheduler for organising themselves, the spreadsheet of attendance or mark book for organising their pupils and the use of a word processor to make notes on information and events immediately they are encountered. This electronic record was valuable as students could use it when they formally wrote up their experiences at a later date.

However, internet access via the portable device was the application that the students considered to be most helpful to both teaching and learning. It was concluded that having the internet literally 'in the hand' affords access to tools and information in a way that does indeed function as distributed intelligence. The student plus PDA meets the person-plus description originally put forward by Perkins (1993) - they are able to do more than they can alone or with other resources. This is due to having ubiquitous access to internet as well as other electronic records and the less obtrusive nature of device. It appeared to be a particular benefit that the PDAs could be kept hidden in a pocket or handbag, at the student teacher's side instantly when needed and returned to the pocket once the need was gone, unlike other information and communications technology (ICT) hardware that sits looming large in the classroom and demanding attention. 
But as Wertsch (1998) points out whether this potential will be realised will depend on the prevailing socio-cultural context and in this case where schools are not open to integrated use of the device, and/or students see the device as offering an unacceptable overhead in terms of ease of use or unfamiliarity, or failure of integration, the person-plus will not in fact be realised.

\section{Introduction}

Benefits of giving students access to internet enabled Personal Digital Assistants (PDAs) or handheld computers have been identified by JISC (2005) whose review of innovative practice with e-learning in further and higher education within the UK suggests that portability, any time, any place connectivity and immediacy of communication are key. JISC (ibid) report that three aspects - portability since PDAs are pocket sized, any time/any place connectivity as PDAs enable flexible and timely access to e-learning resources and immediacy of communication through 'phone or email - are leading to empowerment and more effective management of learners (especially in dispersed communities). Examples include three Further Education colleges in Yorkshire, where PDAs are being used to support students in outreach and work based learning. There the PDAs are seen to be supporting self-paced learning and students' development of personal organisation skills. At the University of Bristol, where undergraduate Economics students accessed course documentation, announcements, email and discussion boards successfully from the University’s Virtual Learning Environment (VLE) via internetenabled PDAs (Ramsden, 2005). Here, as well as enabling access to course resources any time, anywhere, having the PDA allowed the students to hold question and answer sessions via the online discussion board during lectures which they found this particularly helpful. Barak, Lipson, and Lerman (2006) suggest that the value of using portable computing technologies in lecture halls is in promoting active learning. They found use of wireless laptops enhanced student-centred, hands-on, and exploratory learning, as well as the meaningful student-to-student interactions seen in this study.

Other case studies have identified activities where student use of PDAs rather than laptops has been supportive to their learning; in 2001 and 2002 the University of South Dakota issued Palm based PDAs to their incoming cohort of students (Hackemer and Peterson, 2005). This initiative was severely hampered by a lack of the necessary underpinning infrastructure but the development of course syllabi in hypertext format, learning review quizzes, GPS based field 
work in science and anthropology and peer evaluation of presentations where the students beamed their reviews to the speaker's PDA were all reported by students to be successful. The use of PDAs to make the link between field and college based study has also been highlighted as particularly motivating by de Crom and de Jager (2005). They were particularly impressed by their eco-tourism students who, having used their PDAs to take notes and photographs all day in “the bush”, unexpectedly started to write up their reports for the next University seminar, again using the PDA, on the bus back to campus.

Working with PDAs is not always successful; Trinder, Magill and Roy (2005) point to a host of issues. The need to remember to recharge the battery and to synchronise with the host computer are common to both Windows and Palm based systems, as is the small screen size and there is a range of other issues that are platform specific such as the use of an unfamiliar operating system. However, the central theme underpinning the above examples is the presence of the context relevant opportunities that PDAs enable for both autonomous and collaborative learning. In Initial Teacher Training (ITT) we are seeking exactly those context relevant learning opportunities for our students during their teaching practice in schools.

Naismith et al (2004) introduced a classification of mobile learning activities where they categorised examples of learning via PDAs and mobile 'phones that involved children and the general public as well as university and college students, into six areas, four of which relate to the underpinning learning theory. These are behaviourist, constructivist, situated and collaborative. Two further categories relate more to context and application; informal and lifelong learning, and learning and teaching support. This last area of learning and teaching support is particularly relevant to ITT where students move between college and school placement, expected to acquire, decipher and understand a wealth of information, both pedagogical and practical, in the process. Students of other professions where training also requires access to sizable quantities of information (such as medicine and the law) have already found PDAs useful in that they can deliver information directly to the individual as and when required (Manhattan Research, 2002). The use of PDAs may be particularly relevant to the student teacher, who is expected to teach as well as learn, as previous work with teachers using PDAs in schools (Perry, 2003) has shown that PDAs can be supportive of teaching in that they offer considerable potential to make teachers' management and presentation of information more efficient. One Science teacher reported to Perry that "I would never willingly go without 
one now; it is my instantly accessible encyclopaedia, thesaurus, periodic table, diary, register/mark book, world map and even star chart!”.

Learning and teaching support for an ITT student via a PDA is grounded in the ability to access information exactly when and where it is needed to support teaching or learning. This information may come from an electronic book, dedicated science software or the Web, especially via a course linked VLE, or from previously recorded pupil data or via communications with peers and tutors. Thus the communications capability is a key feature of the PDA in this context for, as first proposed by Pea (2002), the PDA is acting as a communication channel enabling highly interactive conversations and access to archives of information, knowledge, and representations of past activities that can be read, drawn upon, and extended as needed. Pea (ibid) also suggested that information technologies can act as cognitive tools for augmenting human performance in complex tasks and for learning. This resonates with Wertsch's (1998) claim that that all human action is mediated by four kinds of tools one group of which comprises technologies such as the PDA or desktop computer. The other groups are semiotic systems such as language including diagrams, social interactions such as those between student and class or student and teacher and institutional structures such as school ICT policy. Within this context the idea of 'person-acting-with-mediationalmeans' (Wertsch, 1991) both implies the previously described augmented capability of the student teacher through use of the PDA but also suggests that their actions are situated and mediated and so will be constrained by their current social and cultural context. Gado, Ferguson and van't Hooft's (2006) recent work on conditions and factors that affect preservice teachers' decisions to use handheld computers in scientific investigations supports the importance of considering context. They found it to be one of five conditions that can affect the integration of handheld technology for instruction and learning. The conditions were (a) the classroom and school environment (physical and social), (b) teachers' technological background and predisposition, (c) students' prior knowledge and experience, (d) having an open and engaging curriculum, and, perhaps obviously, (e) access to handheld computers as learning tools. Interestingly they also found that use of handheld-based science activities also enhanced pre-service teachers' inquiry abilities, organizational skills, engagement in science content learning, and attitudes and self-efficacy.

Further reflection on how a PDA may augment the performance of a teacher trainee through provision of learning and teaching support via access to syllabi, scientific data, news items, glossaries, other experts and tutors leads to a particular focus on distributed information 
sources or knowledge. Pea (1993) went so far as to suggest the use of information and communications technology (ICT) affords distributed intelligence. Perkins (1993) aptly described such working as 'Person Plus'; therefore, the study described in this paper aims to identify

- whether the student teacher plus internet enabled PDA is indeed a 'person plus',

- which aspects of the PDA software and hardware support this notion and therefore, where the PDA can provide learning and/or teaching support

- whether student teachers will engage in collaborative learning if given a communications tool

- whether social or cultural constraints impact upon their PDA use.

\section{Method}

In order to identify where and to what extent the potential for learning and teaching support and collaborative learning (Naismith et al, 2004) can be realised for initial teacher trainees using the current generation of PDAs, fourteen students on the Postgraduate Certificate of Education (PGCE) one-year teacher training course at the University of Bristol were given handheld computers with mobile phone connectivity and cameras to use throughout their course and to take with them on teaching practice.

The 14 students were given either a Windows Pocket PC or a Palm OS based handheld and four hours of training in its use. During this training they were shown how the PDAs have the potential to support them in:

- collaborating via the VLE (Blackboard) discussion groups and email;

- accessing course documentation (on PDA or via Blackboard or via synchronisation (synching) with a PC);

- just in time acquisition of knowledge from the web;

- acquisition of science information from e-books and encyclopaedias;

- delivering accurate figures for scientific constants and formulae;

- organising commitments, lesson plans and timetables;

- recording and analysing laboratory results;

- recording pupil attendance and grades;

- photographing experiments for display and reinforcing pupil knowledge; 
- maintaining a reflective web log (blog) that could allow them to record lesson evaluations and other reflections on their teaching.

The students were chosen from around 20 volunteers from the PGCE cohort of 55, all of whom were experienced ICT users with a home PC and internet access, by selecting randomly from a stratified sample in order to create a mixed group. The final group comprised 4 biologists, 5 chemists and 5 physicists and included 6 males and 8 females. One of the students had used a PDA before and they had all used Word, Excel and Powerpoint in their studies and/or work. Their teaching practice schools ranged from South Wales to Somerset and included private as well as government maintained schools.

Students received PDAs chosen from the range then available in the UK that could deliver web browsing via the internet, email, SMS text messaging, word processing, spreadsheet management and picture messaging. These comprised four Tungsten Ws and two Treo 600s running Palm OS, five Qtek 2020s and 3 i-mates running Pocket PC 2003 (both the latter are SIM free XDA II clones). The PDAs were supplied with aluminium protective cases and screen protectors. Separate collapsible keyboards were also originally provided for all the Pocket PC PDAs as they have only the pop-up on screen keyboard and then later for the Treo 600 s as the students found their keys too small to write with. Add on cameras were also obtained for the Tungsten Ws as they were the only PDAs without integral cameras.

Mobile phone connectivity was supplied by Vodafone as it had proved reliable in the project area in a pilot test. It was arranged that students could receive and send up to a total of $6 \mathrm{MB}$ data including web pages, emails and texts a month without cost to them though they would be expected to pay for any voice calls they made.

The students were participant action researchers in the project acting on their teaching and learning by means of the PDA and then reflecting on and amending their practice (Wadsworth, 1998); they reported in at first via a weekly online survey and then later by a twice termly survey. Additionally they were encouraged to reflect on their experiences via a diary of use in the form of a web log or 'blog'. There was a dedicated discussion area on Blackboard, the course VLE, should they prefer this method of exchanging information and ideas about the PDA project. Additionally a focus group of all PDA users was organised for 
the end of each of their two blocks of teaching practice in order to collect impressions and share potential uses face to face.

\section{Results}

At the point that the students had just completed their first four week teaching practice, the results of the weekly online survey indicated that they recognised that the PDA can enable effective learning support and teaching support. Some students found great value in having the PDA for both their practical teaching in the field and in their learning about teaching and the underpinning pedagogy. Others reported that whilst they recognised the potential they had not been successful in using the PDA in the way they had hoped. As the academic year progressed PDA use tailed off with three students dropping out of the study and eight using them for a smaller range of applications.

Forty-one entries out of a possible 56 were made in the online survey during the first four week teaching practice giving a return rate of $73 \%$. Later in the academic year, having swapped to reporting twice termly, 26 entries out of a possible 42 were still made in the online survey making the return rate for the second teaching practice $62 \%$. Unless otherwise specified the following figures display results from both teaching practices.

The survey results indicate that the pattern of most frequently used software applications remained similar throughout the academic year. The most commonly used applications, as shown in Figure 1, were the diary scheduler and the email client followed closely by the web browser and the word processor whether Palm or Windows based.

\section{$\leftarrow$ Figure 1. The most frequently used software applications (shown as a proportion of the 67 responses from 14 students) about here $\rightarrow$}

These were followed by the use of spreadsheets for recording attendance and grades and the 'to do' or task list. Interestingly, the use of spreadsheets gained slightly in popularity during the study as participating students shared their ideas and templates. For similar reasons the 'to do' or task list lost popularity as the students largely swapped to using the calendar function to record tasks as they could set reminders for deadlines.

Figure 2 shows the results when PGCE students were asked to identify the software that was most helpful in supporting their teaching. 


\section{$\leftarrow$ Figure 2. Software that was most helpful to actual teaching about here. $\rightarrow$}

When considering what software was most supportive for actual teaching of lessons the PDA's own calendar or diary software was mentioned often. One student explains why,

“The calendar and task functionality has been extremely useful. My timetable is surprisingly fluid, with various planning and review meetings being scheduled and re-scheduled - any paper diary would be unreadable and unusable. The task list helps me effectively track and manage the many different tasks that need to be done to survive as a student teacher.”

Also popular for teaching support was the use of the internet, especially the search engine Google, to look up answers to students’ (and staff's) questions and getting a response within a minute or two. Examples cited included “Where do red robins go in summer?”, "How do starfish reproduce?”, searching for up to date information on cloning and finding the telephone number for the local hands-on science centre. One of the students reported that

"Instant access to the internet has been particularly useful. For example, during one lesson I was able to quickly look up the answer to a pupil’s question - this really helped to keep them engaged and interested in the subject matter (in addition to promoting ICT to them)”.

Whilst the speed of the GPRS connection was not as fast as a desk top computer it was quicker than finding a free computer in another room. The students reported three downloadable applications as being particularly helpful to science teaching. These were Tiny Red Book (at http://www.tiny-red-book.com), a periodic table such as the one associated with Calc98 (at http://www.flosim.com/fsi/download.htm) and a scientific data ebook such as PhysConst. (at http://www.freeware-palm.com/download-physconst-v1-12.html) Two students in their first week of teaching practice reported using their periodic table software successfully to give pupils accurate data almost instantly. Tiny Red Book is a customisable mark book with attendance tracking and a place to record student behaviour. One student particularly benefited from using the attendance tracking to prove a child was absent from their lesson. Three other students used Excel for this purpose. 
Showing presentations from the PDA to the class was only mentioned by one student as the hardware (Margi Presenter to Go) only arrived very late on in the study but in focus group discussion the concept of being able to plug the PDA directly into the data projector was very popular amongst all the students. They felt that being able to show class results in the form of charts, tables or photos would be helpful to their students' learning. This would also be possible if the school would allow students to connect their PDA to the classroom computer if available. However, not all students felt comfortable about asking the school's ICT team for permission to do this and one was told it would not be allowed.

The use of the internet was also the most popular application reported when, as shown in Figure 3, the students were asked to identify the software that was most helpful to their learning on the course. Again Google was prominent in the students' discussions, its simple site design makes it easy to use on a PDA and the briefings supplied alongside the search results often contained enough information to answer the original query without needing to refer to the sites located. Also popular was the use of a word-processor or note-recorder either one of which were regularly used to jot down or record information at the point of reception for later processing into assignments or lesson plans. The effectiveness of this activity is reinforced by this student's report

"During teaching practice I have found myself constantly bombarded with new and noteworthy information (e.g. scientific facts, ideas for teaching approaches, school procedures, evidence for QTS standards etc.). The PDA has allowed me to keep meaningful notes of this information, and structure the information (i.e. file) in a way that allows me to access it easily.”

\section{$\leftarrow$ Figure 3. Software that was most helpful to their learning about here $\rightarrow$}

However, when asked what software was the most use to them, as an individual, the students, as shown in Figure 4 focused on the information management functions of the PDA such as the Task or To Do list, the diary scheduler and the use of email. As another student puts it;

"I formed a comprehensive To Do list and prioritised well - really useful with everything mounting up.”.

\section{$\leftarrow$ Figure 4. Software that was most helpful to you as an individual about here $\rightarrow$}


One particular downloadable software application was recommended by the students: OmniRemote which allows the PDA to remotely control the television and other devices in the home. It also enabled one student to operate the school data projector without having to ask the technician for the use of the remote control. Another student downloaded e-books. She reported;

\footnotetext{
"Using the e-book meant that I could catch a few pages at convenient times, I don't think it can ever take the place of reading books, but it certainly cuts down carrying (my bag is so full of school things that I just couldn't carry around any more books)".
}

One of the most useful aspects of the PDA is the ability to use it wherever you happen to be, and the carry over into elements of student life beyond the course underlines this. Whilst most use, as shown in Figure 5, takes place at home or in the school staff areas, activities such as keeping up to date or even ahead of others in school by accessing the latest educational news on the way in to school and taking photos of local events such as carnivals were reported extremely positively by all the students except one. This student gave up on her PDA, a Treo, early in the main teaching practice citing frustration at the PDA's apparent inability to operate in the way she wished it to as her main reason.

\section{$\leftarrow$ Figure 5. Places where students have used their PDAs about here. $\rightarrow$}

Other useful aspects of having a PDA that emerged during focus group discussion were the 'instant on' feature whereby there the PDA can be used straight way after being turned on unlike a laptop which has to boot up and the fact that it is easily hidden after use.

The PDAs were used immediately in the first week of teaching practice by at least half the students for keeping in touch with the University tutor whilst they were away from campus on teaching practice in school. However, only five of the 14 students continued to use the PDA regularly for contacting others. Table 1 shows how many times the students reported that they used the PDA to communicate with their tutors and peers during the first four week teaching practice. 


\section{$\leftarrow$ Table 1. Numbers of students using the PDA to communicate during their first four week teaching practice and how about here. $\rightarrow$}

The pattern of using email to contact the university tutor and SMS and occasional email to contact other students continued into the main teaching practice but more sporadically. The VLE discussion group was also less well used despite the students spending a longer period separate from each other in partner schools. The students whose use of email dropped reported in focus group discussion that, as they got to know them, they looked to their school based colleagues for learning and teaching support rather than the university tutor. One student remained reliant on his more knowledgeable peers, using the PDA to log onto MSN Messenger on a regular basis and even 'chatted' with medical student colleagues during a biology class to gain answers to pupils’ questions.

Learning support through using web based logs, known as blogs, to encourage reflective practice for recording teaching reflections were even less popular with only one student contributing to one regularly, though a second kept a blog of PDA use for a short while. However, the students reported in focus group discussion that having the word-processor or note recorder on their handheld was actually serving the purpose of recording their reflections on teaching and storing them for later use in written assignments or in tutorials with their school based mentor or university tutor. There appeared to be little desire to put up a blog online for tutors to read and add to.

Not all students continued using the PDAs and, during focus group discussion, two clear themes emerged as to why they were not providing effective learning and teaching support. These were that some students found learning the PDA functions time consuming (this was a particular issue for the non-Windows based devices) and some found having a novel device attracted attention from pupils in a way that conflicted with their perception of their role as student teacher. The three students who gave up on using the PDA identified the following reasons during exit interviews.

o Loss of data when the battery was not recharged for a lengthy period - this happened to at least 3 individuals during vacations and was very disheartening.

o Lack of time to continue to explore the use of the PDA under the pressure of teaching, planning for teaching and researching for and writing up university assignments. One 
student reported "with all the planning, essays etc I haven't had the time to set up other uses for it.”

o Lack of access to suitable computers within school to synchronise the PDA so that students' files could be made available on the school network or for data projection.

o Embarrassment at the attention the PDA attracted from pupils - seen as difficult to handle when still learning how to manage a class.

o Worry about taking the PDA into school where mobile phones are regularly stolen.

o Having purchased a laptop and preferring to use that.

Finally, examples of collaborative learning enabled through the PDAs as proposed by Naismith et al (2004) were rare. Five students communicated via the discussion board on the course virtual learning environment (VLE); however, the posts largely concerned requests for help with software or hardware. Course documents on the VLE were used via the PDA for learning support though, with eight students downloading from the choice of background reading, presenter's slides or course handbooks during the first teaching practice. Six of these students also downloaded materials during the second, main teaching practice. In focus group discussion the students reported that the school science staff was supportive to the extent that they felt no need seek advice from other students. Also each school follows individual curricula meaning that the students were covering different topics from one another. However, the focus groups did allow the students to share their learning about the PDA functionality and during the focus group following their first teaching practice they passed files including a spreadsheet to record attendance and grades amongst the group using Bluetooth.

\section{Discussion}

This study shows that, in the case of ITT students in science, the PDA and especially its information management and communications functions have potential, as identified by Naismith et al (2004) to support both their learning and their teaching. However, this potential was only fully realised for the three students who used the PDAs on a regular basis throughout the year, another eight students used theirs intermittently during the year and three 
gave theirs up. As in Gado, Ferguson and van't Hooft's (2006) study exploring pre-service teachers' decisions to use handheld computers in scientific investigations, context clearly impacted upon the integration of handheld technology for instruction and learning. In this study the level of use of the PDAs appeared to be governed by four main factors:

0 the socio-cultural context of the school environment;

o the pressure of work on a PGCE course;

0 other hardware availability and

o certain 'killer applications'.

The three students that maintained regular use of the PDAs throughout the year were all males who used Excel or Spreadsheet to Go everyday to keep tabs on their classes. One of these students also regularly used the voice recorder to record lesson evaluations for later transcription. They acknowledged the attention raising factor of the PDA cited by other students but pointed out that as they used it everyday the novelty had worn off for their classes. Also these students were at schools where staff were less concerned about viruses and malicious software and allowed the PGCE students to link to school computers. They also made a variety of personal uses of the PDA including, for two of the three, games.

The eight students, who used the PDAs intermittently throughout the year were the most affected by the sociocultural context of being a student in a school. Wertsch (1991) makes it clear that actions mediated by technological tools will be situated within the current social and cultural climate not only of the institution but also of the social interactions between the student teacher, the class and the class teacher. Whilst recognising that having Internet access on the PDA extended their capability to answer questions and plan lessons and having Word enhanced their recording of their observations for later assignments, they tended to feel uncomfortable about the attention gained by using the PDA in class or about asking the school to resolve hardware issues. However, it was of considerable benefit to these students that the pocket sized PDA could be returned to a pocket or bag when it was not wanted. For these students, personal use of the PDA appeared to support their intermittent use of it for the PGCE, and where students could see that the PDA applications were personally relevant they continued to use the Internet and Word in particular to support their teaching and learning. They were also more likely to view the PDA as creating work rather than saving it. Killer personal applications for these students included using the PDA as an alarm clock, as a 
remote control, for SMS (text) messaging and MSN, taking pictures of significant events, online shopping, checking bank balances and having information such as recipes and maps on hand when needed.

Of the three female students who withdrew from the study and handed back their PDA, two gave frustration at the PDA's apparent inability to operate in the way they wished it to as their main reason. It is interesting to note that both of these students were using Palm OS based devices, one a Treo 600 and one a Tungsten $\mathrm{W}$. The students had problems with the need to learn menu structures that differ slightly from the Windows systems and with the way the device displayed web pages. The third student cited a preference, under the pressure of increased teaching in the main teaching practice, to work with pen and paper rather than to use the PDA which she viewed as more time consuming. Learning to teach during a one year PGCE course is a very intensive and stressful experience and it needs to be acknowledged that asking students, even volunteers, to learn to use a PDA at the same time may be adding to that stress.

Ability to access the internet from a range of locations was the application that the students perceived to be most supportive to their learning on the course (shown in Figure 3). Also popular though was the use of the PDA for note-taking at convenient points for later processing into assignments or lesson plans. Two applications were perceived equally as most supportive for teaching, shown in Figure 2, internet access (again) and the use of the calendar or diary scheduler. Having internet access enabled the student teachers to look up answers to pupils' more unusual questions on the spot and having the calendar or diary supported their organisation for teaching. In fact the calendar function when combined with the task list was reported as one of the most personally supportive applications as shown in Figure 4. The other application reported as supportive to the individual was having access to email wherever they were. This is corroborated by the finding that the most commonly used applications, throughout the year, as shown in Figure 1, were the calendar or diary scheduler and the email client followed closely by the web browser and the word processor whether Palm or Windows based. However, instances of the PDAs affording collaborative learning also suggested by Naismith et al (2004) were rarer with email and the VLE discussion boards being largely used to send and receive information for day to day task management. 
It is clear that when the students had the internet enabled PDAs out in the staff room or classroom they did indeed become 'people plus' as described by Perkins (1993) with access to interactive conversations and archives of information, knowledge, and representations of past activities (Pea, 1993). One unanticipated bonus was that the pocket sized device could quickly be hidden when the student felt the environment was inappropriate for PDA use.

\section{Conclusions}

For most of the ITT students the PDA afforded both learning and teaching support (Naismith et al, 2004) whenever they used it. Though not all students used the PDA regularly throughout the academic year there is clear potential for the devices due to their portability, any time/any place connectivity to stored information and immediacy of communication (JISC, 2005). In fact Perkins' (1993) concept of 'Person Plus' can usefully be used to describe the distributed intelligence system encompassing the knowledge of the student science teacher plus the course resources, scientific data and pupil information stored either on the PDA or accessed as and when needed from the internet. In particular the ease of use of Google and MSN for accessing the web and more knowledgeable peers via the PDA was impressive. The use of pocket-sized, portable ICT devices to extend personal capability in this way is truly ICT at your side and not 'in your face'; they are easily slipped into a pocket or bag when not needed.

The software applications most able to support Perkins' (1993) notion of 'person plus' were found to be the calendar or diary, email, the web browser and the word processor. The calendar or diary was deemed particularly supportive and used mainly for scheduling and making notes on appointments but occasionally for timetabling. Email was used primarily to maintain contact with other students and the university tutor. Examples of students emailing each other for assistance with a particular project indicate that having the PDAs is capable of affording instances of collaborative learning as defined by Naismith et al (2004) as well as learning and teaching support. The web browser was used to access information both in class and for personal reasons. The wealth of information on the internet means it can be used to answer virtually any question and whilst the GPRS bandwidth was not as fast as a broadband connection the delay was acceptable both to the PGCE students and their pupils. It was discovered that you can even use a PDA surreptitiously in a lesson or meeting to look up the topic under discussion or to 'chat' with experts without overtly appearing absent minded or 
particularly unintelligent. The word processor was used to make notes from meetings, on lesson observations for essays and to record lesson evaluations and the spreadsheet management system to record pupils’ attendance and grades.

However, three of the students gave up on using the PDAs citing difficulties in becoming familiar with its use and a preference for using pen and paper. Other factors to be considered include the socio-cultural context of PDA use; currently PDAs are rare in schools. One student found the interest it generated amongst the pupils detracted from her teaching and a number of them have reported a feeling of no-one to share their m-learning practice with in the classroom. Several reported feeling uncomfortable about asking for technical support in linking the PDA to the school hardware from the school ICT technicians. Also an ITT course is an extremely busy time - the students that gave up on the PDAs described the course demands as preventing them from devoting time to necessary exploration of the PDA functionality. One issue that prevented more students taking pictures to use in their teaching was concern about the number and level of permissions required to photograph children.

Looking to the future, as PDA prices are already coming down it is clear that personal ownership of internet enabled PDAs, whether wireless or mobile phone, is on the increase. The personal computer and mobile phone are merging with the PDA on one side and the Smartphone on the other. Where universities are aiming to deliver course based content to students such as teacher, nurse, veterinary and medical trainees in the field or supporting students on sandwich courses during their industrial placement this small scale study shows there is great potential for enhancing student learning by making the course content accessible via any or all of these handheld devices.

In particular, recommendations for future development of PDA use by teachers and trainee teachers include:

o ensuring 'always on' internet access;

0 investing in a larger community of practice;

o enabling connection with the classroom data projectors;

o designing bespoke software that allows both timetabling and personal appointments;

o allowing synchronisation with the school network computers;

0 more use of video and images; 
0 encouraging personal use and

o focusing on making students comfortable with 'killer applications' such as attendance registers, markbooks and maintaining an online audit of Qualified Teacher Status standards.

Once these conditions are met it seems that a small personal internet connected device can indeed offer support to student teachers in practice and support them to act as 'teacher-plus'.

\section{References}

Barak, M., Lipson, A. and Lerman, S. (2006) Wireless Laptops as Means For Promoting Active Learning In Large Lecture Halls, Journal of Research on Technology in Education, 38 (3), 244-263.

de Crom, N. and de Jager, A. (2005). The “ME”-Learning Experience: PDA Technology and eLearning in Ecotourism at TUT. Paper presented at Mlearn’05, October 2005, Cape Town

Gado, R., Ferguson, R. and van’t Hooft, M. (2006) Inquiry-Based Instruction Through Handheld-Based Science Activities: Preservice Teachers' Attitude and Self-Efficacy, Journal of Technology and Teacher Education, 14 (3), 501-529.

Hackemer, K. and Peterson D. (2005) University of South Dakota Palm Initiative in Kukulska-Hulme, A. and Traxler, J. (Eds) Mobile Learning: A Handbook for Educators and Trainers (London, Routledge)

JISC (2005) Innovative Practice with e-Learning. (Bristol, Higher Education Funding Council for England (HEFCE)). Available online at http://www.jisc.ac.uk/eli_practice.html [accessed 6 March 2006]

Manhattan Research (2002) Taking the Pulse: Physicians and Emerging Information Technologies. Available on line at www.manhattanresearch.com [accessed 26 May 2004]

Naismith, L., Lonsdale, P., Vavoula, G. and Sharples, M. (2004) Report 11: Literature Review of Mobile Technologies in Learning. Bristol: Futurelab. Available on line at http://www.futurelab.org.uk/research/reviews/reviews_11_and12/11_01.htm [accessed 24 July 2006]

Pea, R.D. (2002) Learning Science through Collaborative Visualization over the Internet. Paper presented at Nobel Foundation Virtual Museums Symposium, Stockholm, May 26-29.

Pea, R. D. (1993). Practices of distributed intelligence and designs for education, in G. Salomon (Ed.) Distributed cognitions (New York, Cambridge University Press), 47-87.

Perkins, D. N. (1993). Person-plus: A distributed view of thinking and learning. In G. Salomon (Ed.) Distributed cognitions (New York, Cambridge University Press), 88-110. 
Perry, D. (2003) Handheld Computers PDAs in Schools (Coventry: British Educational Communications and Technology Agency). Available online at http://www.becta.org.uk/page_documents/research/handhelds.pdf [accessed 6 March 2006]

Ramsden, A. (2005) Evaluating a PDA for Delivering VLE Functionality in KukulskaHulme, A. and Traxler, J. (Eds) Mobile Learning: A Handbook for Educators and Trainers (London, Routledge)

Trinder, Magill and Roy (2005) Expect the Unexpected in Kukulska-Hulme, A. and Traxler, J. (Eds) Mobile Learning: A Handbook for Educators and Trainers (London, Routledge)

Wertsch, J. (1991) Voices of the Mind; A Sociocultural Approach to Mediated Action (London, Harvester)

Wertsch, J. (1998) Mind as Action (New York, Oxford University Press Inc)

Wadsworth, Y. (1998) What is Participatory Action Research? Action Research International, Paper 2. Available online at http://www.scu.edu.au/schools/gcm/ar/ari/p-ywadsworth98.html [accessed 24th July 2006] 
Figure 1. The most frequently used software applications (shown as a proportion of the 67 responses from 14 students)

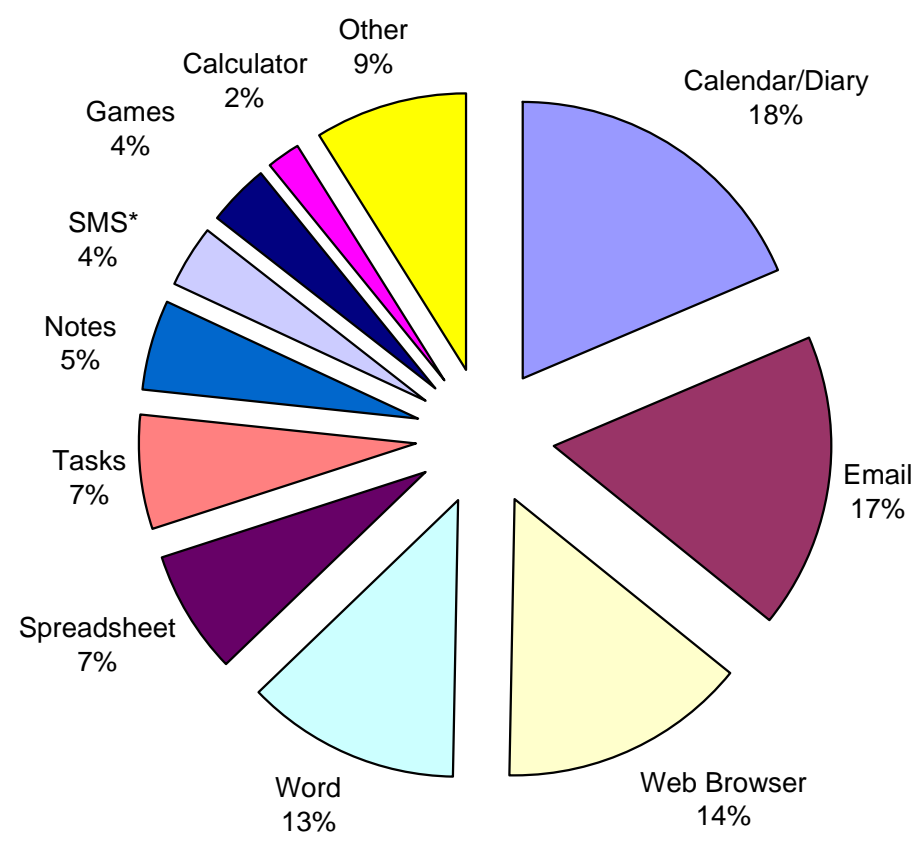

*Short Messaging Service (text messaging). 
Figure 2. Software that was most helpful to actual teaching (shown as a proportion of 54 responses from 14 students).

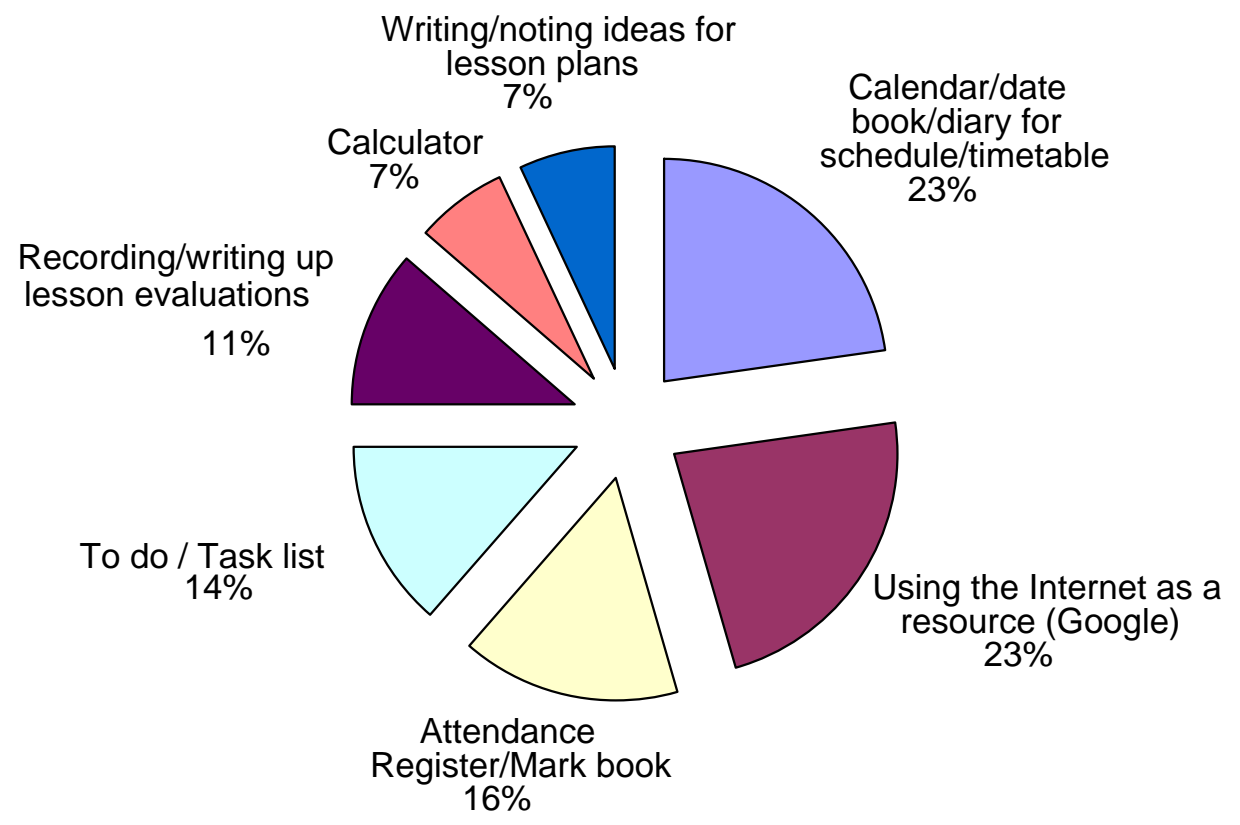


Figure 3. Software that was most helpful to their learning (shown as a proportion of 55 responses from 14 students)

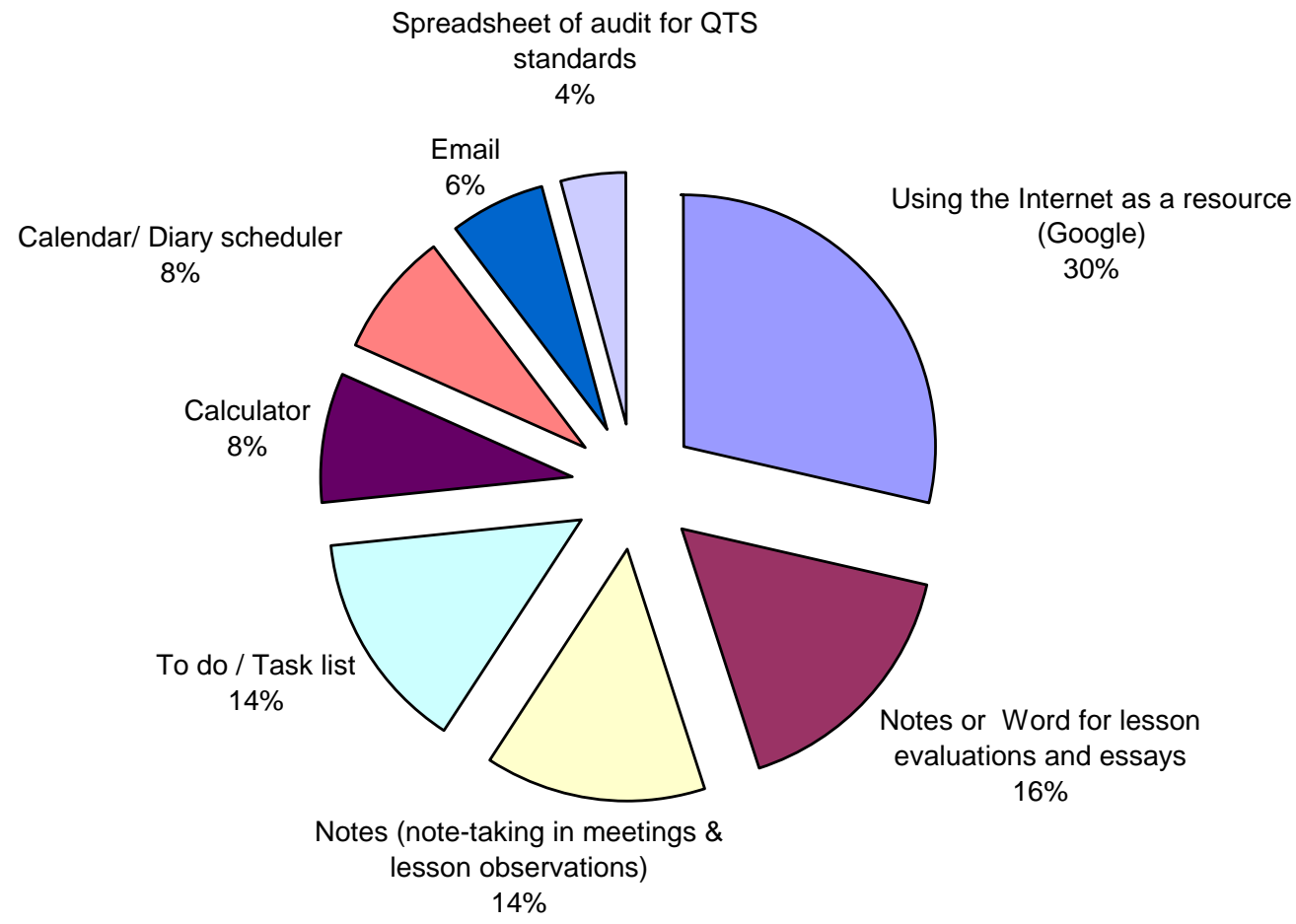


Figure 4. Software that was most helpful to you as an individual. (shown as a proportion of 58 responses from 14 students)

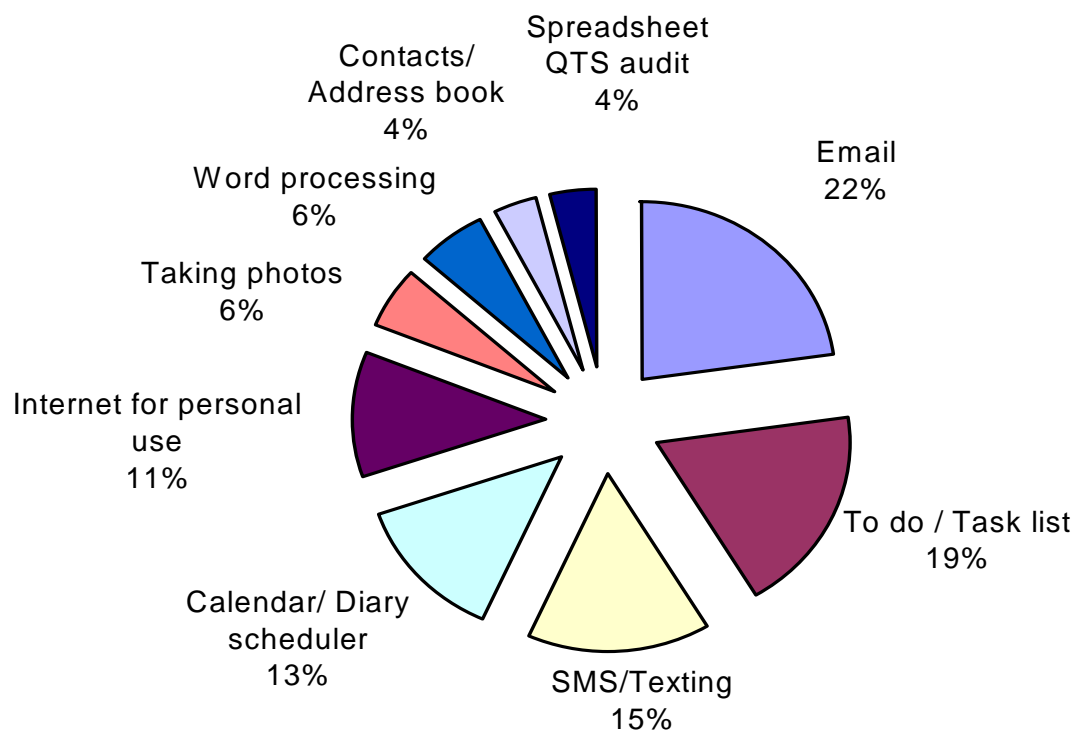


Figure 5. Places where students have used their PDAs (number of times each location was reported in the 67 responses to the online surveys).

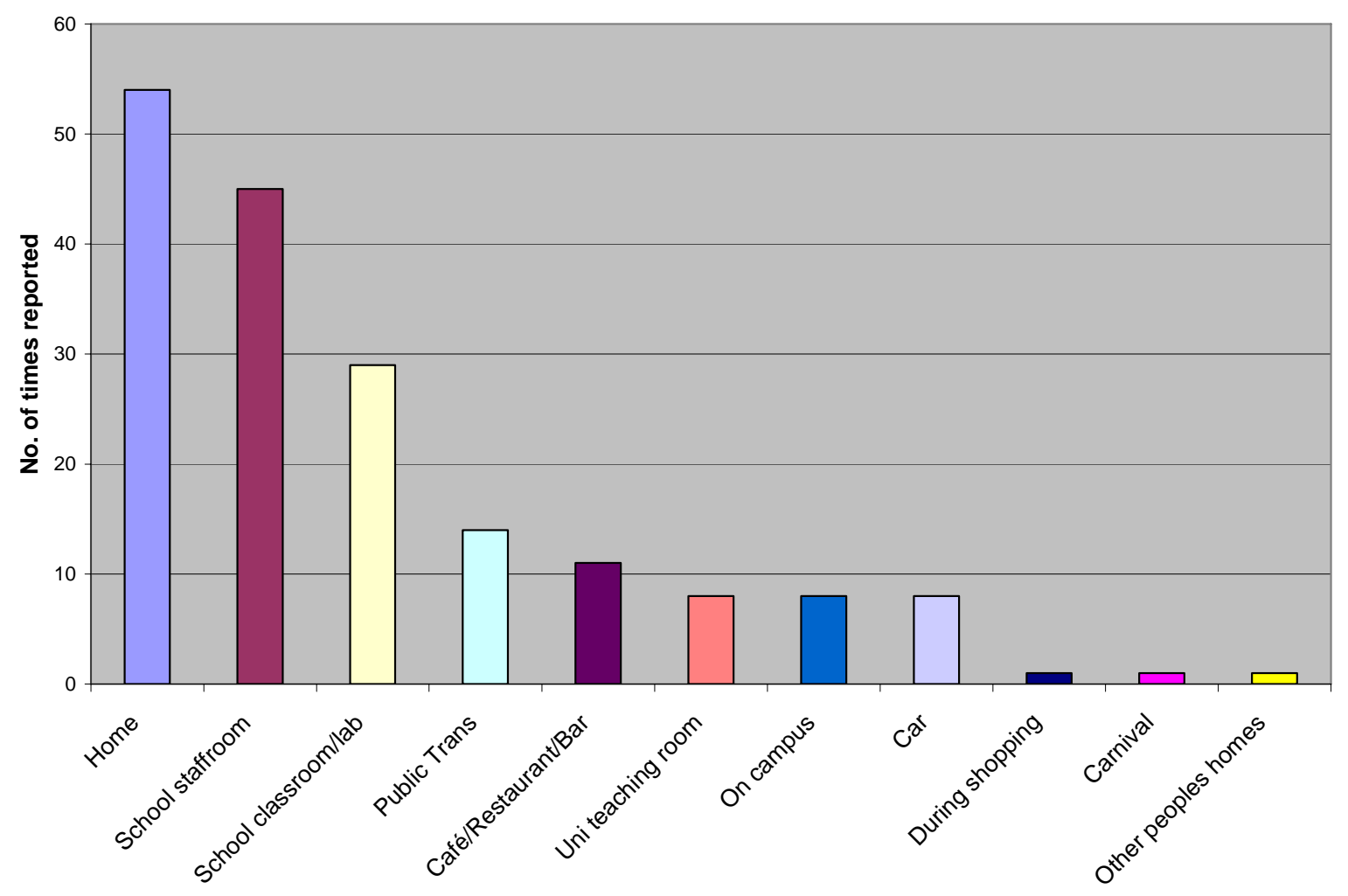


Table 1. Numbers of students using the PDA to communicate during their first four week teaching practice and how $(n=42)$.

\begin{tabular}{|l|r|l|l|}
\hline & $\begin{array}{l}\text { email on } \\
\text { PDA }\end{array}$ & $\begin{array}{l}\text { SMS* on } \\
\text { PDA }\end{array}$ & $\begin{array}{l}\text { VLE discussion } \\
\text { group (via PDA) }\end{array}$ \\
\hline University tutor & 15 & 0 & 5 \\
\hline School based mentor & 2 & 0 & 0 \\
\hline Other PGCE students & 18 & 8 & 5 \\
\hline
\end{tabular}

*Short Messaging Service (texting). 